\title{
The epidemiology of envenomation via snakebite in the State of Piauí, Northeastern Brazil
}

\author{
Nayana da Rocha Oliveira ${ }^{[1]}$, Ana Clara da Rocha Sousa ${ }^{[1]}$, \\ José Francisdavid Barbosa Belmino ${ }^{[2]}$, Sanny da Silva Furtado ${ }^{[2]}$ \\ and Renner de Souza Leite ${ }^{[1]}$
}

[1]. Unidade Acadêmica de Saúde, Centro de Educação e Saúde, Universidade Federal de Campina Grande, Cuité, PB. [2]. Unidade Acadêmica de Educação, Centro de Educação e Saúde, Universidade Federal de Campina Grande, Cuité, PB.

\begin{abstract}
Introduction: This communication describes a retrospective study of the epidemiology of snakebite cases that were recorded from 2007 to 2012 in the State of Piauí, northeastern Brazil. Methods: Data were collected from the Injury Notification Information System database of the State of Piauí's Health Department. Results: A total of 1,528 cases were identified. The cases occurred most frequently in rural areas between January and July. Victims were predominantly male farmers, and were typically 30-39 years old. Most victims were bitten on the foot, and received medical assistance within 1-3h after being bitten. Conclusions: The epidemiological profile of snakebites in the State of Piauí is similar to that in all of Brazil.
\end{abstract}

Keywords: Epidemiology. Human envenomation. Snakes.

Envenomation via snakebite is a worldwide public health problem, particularly in tropical and subtropical countries, due to its high incidence and potential lethality ${ }^{(1)}$. In Brazil, approximately 30,000 snakebite cases are recorded every year, with an incidence of 16 cases $/ 100,000$ inhabitants $^{(2)}$. The snakebite cases predominately occur during the hot and rainy months, and typically affect 15-49 year old male rural workers, who are mainly bitten on the foot or hand ${ }^{(1)(3)}$. Snakes of the genus Bothrops (Viperidae) are known to be responsible for the majority of snakebite cases, bites by Crotalus (Viperidae) are less frequent, and bites by Lachesis (Viperidae) and Micrurus (Elapidae) are $\operatorname{rare}^{(1)(3)}$. This profile has been reported in many regions throughout $\mathrm{Brazil}^{(1)(3)}$, although the epidemiology of snakebite cases in northeastern Brazil remains poorly understood, due to the underreporting of cases and failures in epidemiological data collection. In addition, various social and environmental changes that have occurred in that region during recent decades indicate that new research is needed regarding this topic.

To address this shortcoming, the current study retrospectively analyzed epidemiological data regarding snakebite cases that were recorded between 2007 and 2012 in the State of Piauí, northeastern Brazil. The State of Piauí is composed of 224

\footnotetext{
Address to: Prof. Renner de Souza Leite. Unidade Acadêmica de Saúde/CES/ UFCG. Olho D’água da Bica s/n, 58175-000 Cuité, PB, Brasil.

Phone: 5583 3372-1900

e-mail: rennerleite@yahoo.com.br

Received 23 July 2014

Accepted 18 August 2014
}

municipalities (Figure 1), with a population of approximately $3,184,166$ inhabitants. Its territory covers an area of $251,577,738 \mathrm{~km}^{2}$, and $82 \%$ of this territory is located within the Drought Polygon, an area that is affected annually by prolonged periods of drought ${ }^{(4)}$. The data were collected from the Injury Notification Information System database of the State of Piauís Health Department. Demographic and population data from the Brazilian Institute of Geography and Statistics were used to calculate the incidence rates for snakebites. Statistical analyses were performed using simple frequency tests, and all statistical analyses were performed using SPSS ${ }^{\circledR}$ software (version 13.0 for Windows, SPSS Inc., Chicago, IL). This study was approved by the Ethics Research Committee of the Federal University of Campina Grande (protocol number 451.867/2013).

Our results provide the first epidemiological profile for snakebites in the State of Piauí. A total of 1,528 snakebite cases were recorded in 113 municipalities between January 2007 and December 2012. Based on these findings, we calculated incidence rates of 7 cases $/ 100,000$ inhabitants in 2007, 6 cases/100,000 inhabitants in 2008, 9 cases/100,000 inhabitants in 2009,8 cases $/ 100,000$ inhabitants in 2010,8 cases $/ 100,000$ inhabitants in 2011, and 7 cases/100,000 inhabitants in 2012 . The greatest number of snakebites was observed in the municipality of Teresina ( $\mathrm{n}=236 ; 15.4 \%)$, followed by Picos $(\mathrm{n}=228 ; 14.9 \%)$, Bom Jesus $(\mathrm{n}=71 ; 4.6 \%)$, Floriano $(\mathrm{n}=56$; $3.7 \%)$, Valença do Piauí $(\mathrm{n}=49 ; 3.2 \%)$, and Dom Inocêncio $(\mathrm{n}=46 ; 3 \%)$ (Figure 1). All other municipalities recorded $<3 \%$ of all snakebites that were reported during the study period.

Interestingly, the incidence of snakebites, regardless of the species involved, varies from country to country and among regions within a country, depending on the climate, ecological 

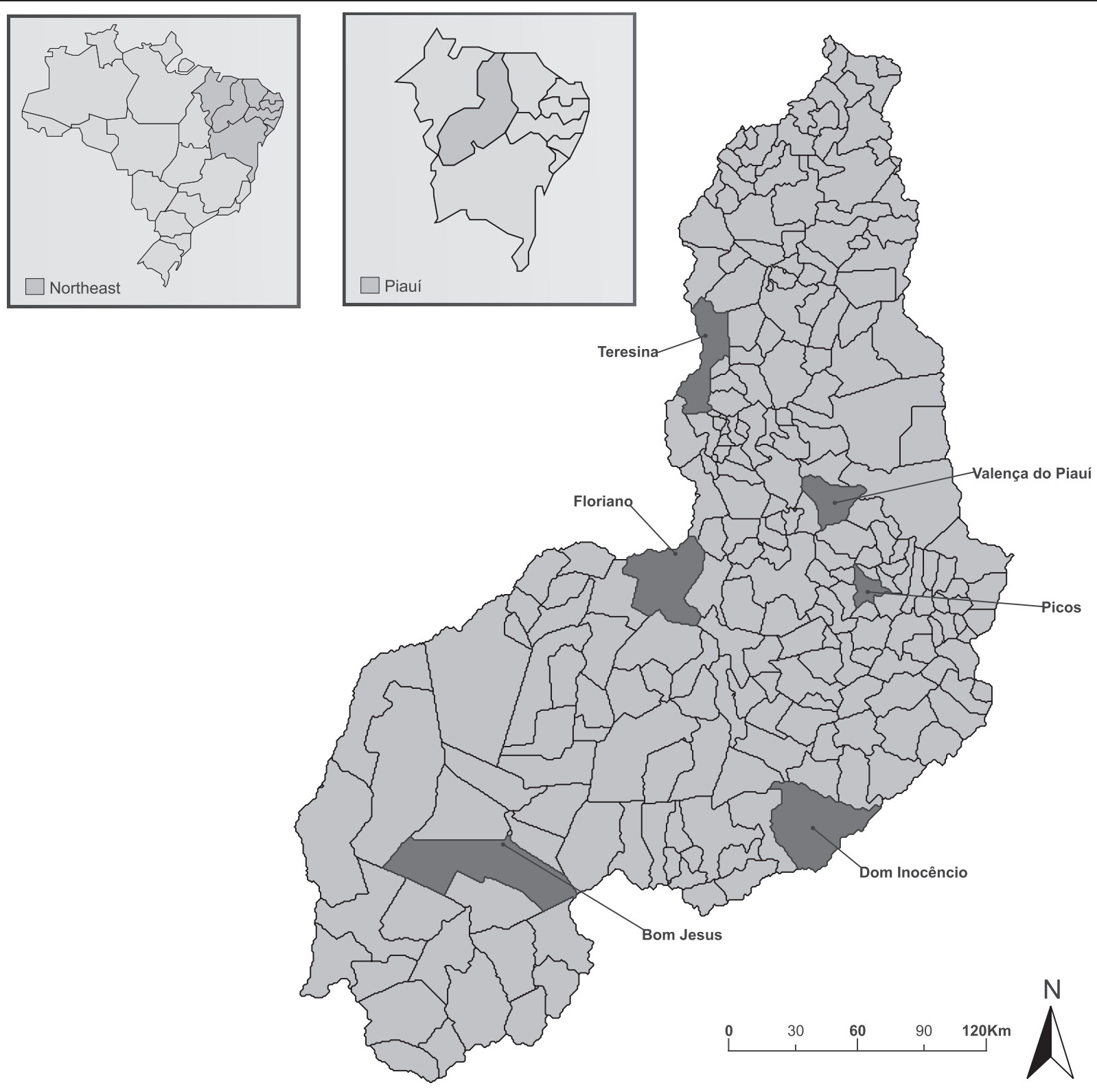

FIGURE 1 - Snakebite cases in Piauí.

parameters, biodiversity, distribution of venomous snakes, human population density, economic activities, and dwelling types ${ }^{(5)}$. The region that we studied has several compounded risk factors for exposure to snakebites, including the high average temperatures and large number of individuals who live in rural areas. Moreover, increased environmental degradation may contribute to the development of desertification processes, thereby reducing the natural habitats for snakes. Although snakebite cases were recorded in all months of the year, they mainly occurred between January and July, which coincides with the rainy period in the State of Piauí( ${ }^{(6)}$. These findings indicate that actions should be taken to prevent snakebites throughout the year, such as effective education programs regarding snakes, snakebites, prevention, and treatment, and that these should be offered to the community residents and health workers ${ }^{(5)}$. However, these efforts should also be intensified during the months of peak incidence. The increased number of snakebites during the rainy period has also been observed in other northeastern regions of $\mathrm{Bazil}^{(7)}{ }^{(8)}$, as well as in the northern region ${ }^{(9)}$. Similarly, studies regarding the epidemiology of snakebites in the southern ${ }^{(10)}$ and southeastern ${ }^{(11)}$ regions have reported a higher incidence of snakebites during the rainy period, although the rainy season in these regions occurs between October and April.

Table 1 shows that the majority of snakebites occurred in rural areas $(\mathrm{n}=1,276 ; 83.5 \%)$, and involved men $(\mathrm{n}=1,200$; $78.5 \%)$, people with low levels of education $(\mathrm{n}=1,052$; $68.8 \%)$, or people who were $30-39$ years old $(n=277 ; 18.1 \%)$. 
TABLE 1 - Sociodemographic profile of snakebite cases in the State of Piauí between 2007 and 2012.

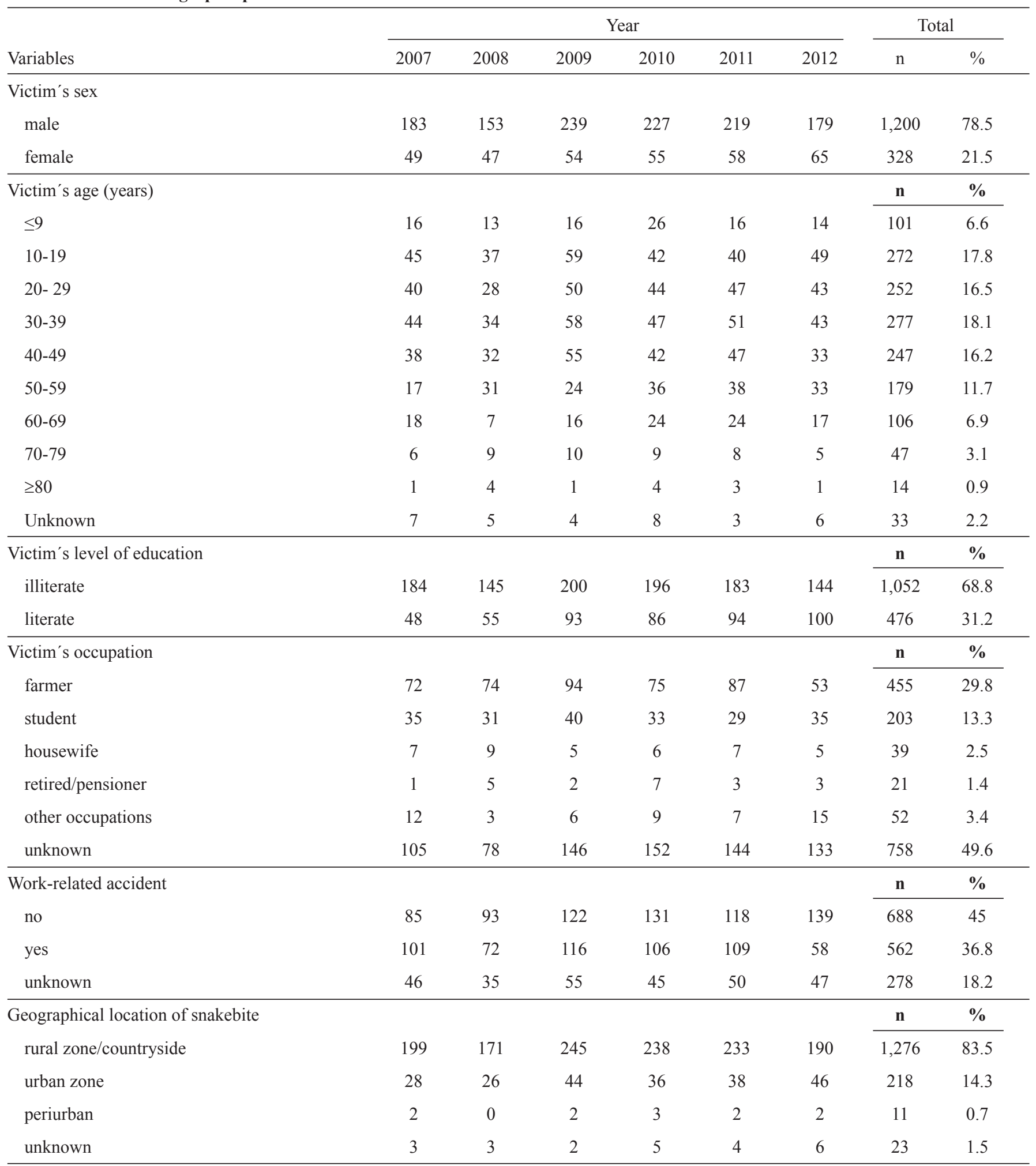

This epidemiological profile is similar to that reported in others studies of ophidism in Brazil ${ }^{(12)(13)}$. Regarding the victims' occupations, the highest percentage of these cases involved farm workers $(n=445 ; 59.8 \%)$. Therefore, the relationship between snakebites, the rainy season, and farm labor reinforces the classification of these snakebites as labor-associated accidents ${ }^{(12)}$. Furthermore, rural areas are more severely affected by snakebites, and exhibit high morbidity and mortality rates, which is related to these communities' higher exposure to high-risk areas and difficulties in accessing health centers that 
can provide snake antivenom. Unfortunately, the economic impact of these injuries is considerable, especially because most of the victims are young ${ }^{(14)}$, that is, they are representative of the economically active population.

Table 2 shows that the largest group of victims received medical assistance within $3 \mathrm{~h}$ after the snakebite $(\mathrm{n}=545$; $35.7 \%$ ), and that 235 (15.4\%) patients received treatment within the first hour. Earlier Brazilian studies ${ }^{(8)}{ }^{(12)}$ have reported that $>80 \%$ of snakebite victims are attended to within $6 \mathrm{~h}$ after the bite. However, our finding that $20.1 \%$ of victims received medical care $>6 \mathrm{~h}$ after being bitten indicates that patients are not well informed, and that the healthcare system is not suited to managing snakebites in these regions. The majority of cases were successfully treated $(n=1,300 ; 85 \%)$, although there were 19 recorded deaths. The blood clotting time test was performed for $328(21.5 \%)$ patients, with normal results $(<10 \mathrm{~min})$ in 246 $(16.1 \%)$ patients and abnormal results $(10-30 \mathrm{~min})$ in $82(5.4 \%)$ patients. These alternations in the blood coagulation rate are in agreement with previously reported data ${ }^{(8)}(9)$. The most frequently bitten part of the body was the foot $(\mathrm{n}=658 ; 43.1 \%)$,

TABLE 2 - Epidemiological profile of snakebite cases in the State of Piauí between 2007 and 2012.

\begin{tabular}{|c|c|c|c|c|c|c|c|c|}
\hline \multirow[b]{2}{*}{ Variables } & \multicolumn{6}{|c|}{ Year } & \multicolumn{2}{|c|}{ Total } \\
\hline & 2007 & 2008 & 2009 & 2010 & 2011 & 2012 & $\mathrm{n}$ & $\%$ \\
\hline \multicolumn{9}{|l|}{ Affected part of the body } \\
\hline foot & 106 & 88 & 116 & 127 & 125 & 96 & 658 & 43.1 \\
\hline leg & 37 & 35 & 44 & 44 & 60 & 45 & 265 & 17.3 \\
\hline hand & 19 & 23 & 34 & 40 & 26 & 38 & 180 & 11.8 \\
\hline toe & 25 & 18 & 43 & 27 & 38 & 17 & 168 & 11 \\
\hline finger & 25 & 14 & 27 & 18 & 15 & 25 & 124 & 8.1 \\
\hline forearm & 8 & 5 & 4 & 7 & 5 & 8 & 37 & 2.4 \\
\hline arm & 4 & 4 & 6 & 6 & 2 & 3 & 25 & 1.6 \\
\hline thigh & 1 & 3 & 3 & 1 & 1 & 3 & 12 & 0.8 \\
\hline head & 1 & 1 & 4 & 0 & 2 & 3 & 11 & 0.7 \\
\hline trunk & 1 & 2 & 2 & 2 & 0 & 1 & 8 & 0.5 \\
\hline unknown & 5 & 7 & 10 & 10 & 3 & 5 & 40 & 2.6 \\
\hline Time from bite until assistance (h) & & & & & & & $\mathbf{n}$ & $\%$ \\
\hline$\leq 1$ & 35 & 24 & 40 & 46 & 44 & 46 & 235 & 15.4 \\
\hline $1-3$ & 74 & 76 & 100 & 97 & 104 & 94 & 545 & 35.7 \\
\hline $3-6$ & 61 & 45 & 76 & 57 & 63 & 45 & 347 & 22.7 \\
\hline $6-12$ & 21 & 25 & 19 & 25 & 22 & 12 & 124 & 8.1 \\
\hline $12-24$ & 17 & 9 & 20 & 17 & 7 & 9 & 79 & 5.2 \\
\hline$\geq 24$ & 12 & 10 & 20 & 21 & 26 & 15 & 104 & 6.8 \\
\hline unknown & 12 & 11 & 18 & 19 & 11 & 23 & 94 & 6.1 \\
\hline Coagulation time & & & & & & & $\mathbf{n}$ & $\%$ \\
\hline unrealized & 157 & 123 & 201 & 179 & 175 & 130 & 965 & 63.2 \\
\hline normal & 42 & 28 & 44 & 52 & 51 & 29 & 246 & 16.1 \\
\hline altered & 12 & 14 & 14 & 19 & 9 & 14 & 82 & 5.4 \\
\hline unknown & 21 & 35 & 34 & 32 & 42 & 71 & 235 & 15.4 \\
\hline Antivenom & & & & & & & $\mathbf{n}$ & $\%$ \\
\hline yes & 193 & 169 & 234 & 221 & 237 & 183 & 1,237 & 81 \\
\hline no & 28 & 26 & 43 & 47 & 27 & 43 & 214 & 14 \\
\hline unknown & 11 & 5 & 16 & 14 & 13 & 18 & 77 & 5 \\
\hline
\end{tabular}


and similar results have been reported for other Brazilian regions $^{(9)(12)}$. This finding indicates that there is suboptimal use of suitable protective equipment (e.g. boots, gaiters and gloves), particularly in rural areas where non-mechanical agricultural labor is common. Antivenom (between 2 and 10 ampoules) was used for most (81\%) victims, although 214 (14\%) patients did not receive antivenom.

Various failures were identified in the patients' medical records. These included a high proportion of cases in which the genus of the snake was not reported, failure to note the time of day when the snakebite occurred, the victim's clinical progression, and the time that elapsed between the bite and the initial treatment. These failures may be related to the unusually high demands placed on health centers and the lack of time to accurately complete the medical records, probably due to the small number of workers. Therefore, these suboptimal situations should be emphasized, as they are common to all healthcare centers in northeastern Brazil and contribute to incomplete patient records. The small municipalities in northeastern Brazil, especially those with fewer than 25,000 inhabitants and that are distant from large urban centers, generally have few qualified health workers or staff who are able to properly collect information regarding snakebite cases. Therefore, treatments that involve serious health problems and/or emergencies (e.g., snakebites) increase the chances of incomplete patient information, especially where the health services infrastructure is minimal. However, recording medical information is often not prioritized in Brazil, even under optimal conditions, and this frequently results in improperly filed and stored records. Unfortunately, this practice is common, even in university hospitals, where many medical records are poorly filled out and lack the necessary information ${ }^{(15)}$. This situation is perpetuated by the fact that the curricula of university courses in medicine, nursing, and pharmacy almost always lack instruction on envenomation via venomous animals, as well as the health of rural workers in are not satisfactorily considered in university courses regarding agronomy and veterinary medicine. Therefore, our data regarding the snakebite epidemiology in northeastern Brazil appears to indicate that better training for health professionals is needed, as well as more suitable protocols for recording epidemiological information in snakebite cases. Without the basic infrastructure and training, it will be difficult to gather any precise information regarding the snakebite-related health challenges for towns and villages in northeastern Brazil, the risk factors involved in this type of envenomation, or the logistics that are needed for appropriate distribution of antivenom.

In conclusion, our results indicate that the epidemiological profile of snakebites in the State Piauí is similar to that observed throughout Brazil. Snakebites mainly occurred in rural areas, during the rainy season, and predominantly affected adult male farmer workers who had a low level of education. Furthermore, most victims were bitten on the lower limbs. This information regarding the regional incidence of snakebites and the epidemiological profile of the victims is essential for evaluating this issue and developing public policies to reduce the number of snakebites and improve the medical care for snakebite victims. Therefore, the findings of the current study increase the understanding of snakebite epidemiology in the State of Piauí, and will be useful in identifying the conditions that increase the risk of envenomation via snakebite in northeastern Brazil.

\section{ACKNOWLEDGMENTS}

The authors are grateful to Maria Amélia de Oliveira Costa (State of Piauí Health Department) for providing us with the epidemiological data.

\section{CONFLICT OF INTEREST}

The authors declare that there is no conflict of interest.

\section{FINANCIAL SUPPORT}

This study was supported by the Instituto Nacional de Ciência e Tecnologia em Toxinas (INCTTOX).

\section{REFERENCES}

1. Ministério da Saúde. Manual de diagnóstico e tratamento de acidentes por animais peçonhentos. Brasília: Fundação Nacional de Saúde; 2001.

2. Ministério da Saúde. Secretaria de Vigilância em Saúde. Sistema de Informação de Agravos de Notificação (SINAN) [Internet]. Casos de acidentes por serpentes. Brasil, Grandes Regiões e Unidades Federadas. 2000 a 2011. [Cited 2014 April 10]. Available at http:// portalsaude.saude.gov.br/portalsaude/texto/5817/783/acidentes-porserpentes.

3. Pinho FMO, Pereira ID. Ofidismo. Rev Assoc Médica Brasileira 2001; 47: 24-29.

4. Fundação Centro de Pesquisas Econômicas e Sociais do Piauí (CEPRO). Piauí em Números. 8ª ed. Teresina, PI: CEPRO; 2010. [Cited 2014 June 02]. Available at: www.cepro.pi.gov.br.

5. Otero-Patinõ R. Epidemiological, clinical and therapeutic aspects of Bothrops asper bites. Toxicon 2009; 54:998-1011.

6. Silva VMA, Medeiros RM, Santos DC, Filho MFG. Variabilidade pluviométrica entre os regimes diferenciados de precipitação no estado do Piauí. Rev Bras Geogr Fisica 2013; 6:1463-1475.

7. Albuquerque HN, Fernandes A, Albuquerque ICS. Snakebites in Paraíba, Brazil. J Venom Animals Toxins Incl Trop Dis 2005; 11:242-251.

8. Oliveira HFA, Barros RM, Pasquino JA, Peixoto LR, Sousa JA, Leite RS. Snakebite cases in the municipalities of the State of Paraíba, Brazil. Rev Soc Bras Med Tropical 2013; 46:1-8.

9. Bernarde PS, Gomes JS. Serpentes peçonhentas e ofidismo em Cruzeiro do Sul, Alto Juruá, Estado do Acre, Brasil. Acta Amazonica 2012; 42:65-72.

10. Bochner R, Struchiner CJ. Epidemiologia dos acidentes ofídicos nos últimos 100 anos no Brasil: uma revisão. Cad Saude Publica 2003; 19:7-16. 
11. Rojas CA, Gonçalves MR, Almeida Santos SM. Epidemiologia dos acidentes ofídicos na região noroeste do estado de São Paulo, Brasil. Rev Bras Saude Prod An 2007; 8:193-204.

12. Pinho FMA, Oliveira ES, Faleiros F. Acidente ofídico no Estado de Goiás. Rev Assoc Medica Bras 2004; 50:93-96.

13. Feitosa RFG, Melo IMLA, Monteiro HSA. Epidemiologia dos acidentes por serpentes peçonhentas no estado do Ceará - Brasil. Rev Soc Bras Med Trop 1997; 30:295-301.
14. Kasturiratne A, Wickremasinghe AR, Silva N, Gunawardena NK, Pathmeswaran A, Premaratna R, et al. The Global Burden of snakebite: a literature analysis and modelling based on regional estimates of envenoming and deaths. PLoS Med 2008; 5:1591-1604.

15. Silva FG, Tavares-Neto J. Avaliação dos Prontuários Médicos de Hospitais de Ensino do Brasil. Rev Bras Educ Med 2007; 31:113126. 